\title{
Design-oriented Human-Computer Interaction
}

\author{
Daniel Fallman \\ Department of Informatics and Umeå Institute of Design \\ Umeå University, Sweden \\ SE-901 87 \\ +46907866247 \\ dfallman@informatik.umu.se
}

\begin{abstract}
We argue that HCI has emerged as a design-oriented field of research, directed at large towards innovation, design, and construction of new kinds of information and interaction technology. But the understanding of such an attitude to research in terms of philosophical, theoretical, and methodological underpinnings seems however relatively poor within the field. This paper intends to specifically address what design 'is' and how it is related to HCI. First, three candidate accounts from design theory of what design 'is' are introduced; the conservative, the romantic, and the pragmatic. By examining the role of sketching in design, it is found that the designer becomes involved in a necessary dialogue, from which the design problem and its solution are worked out simultaneously as a closely coupled pair. In conclusion, it is proposed that we need to acknowledge, first, the role of design in HCI conduct, and second, the difference between the knowledge-generating Design-oriented Research and the artifact-generating conduct of Research-oriented Design.
\end{abstract}

\section{Keywords}

Design, Theory, Methodology, Sketching, Prototyping, Design-oriented Research, Research-oriented Design

\section{INTRODUCTION}

Human-Computer Interaction (HCI) has emerged as the primary strand within computing-related research that seems to have at its heart the design of novel information, interaction, and communication technology. Two examples may illustrate the focal position of design in HCI. First, researchers in HCI are frequently involved in designing research prototypes based, for instance, on theories from the cognitive and the social sciences; ethnographic fieldwork; users with special needs, or which simply comes out from novel and innovative ideas. Such prototypes often become designed by necessity, as doing so is the only way researchers are able to set up experiments for testing and evaluating their ideas on an appropriate user group. Second, it is becoming increasingly evident that contemporary HCI is not solely an academic discipline but in effect a field

Please Note: This is a draft version of Fallman, D. (2003) DesignOriented Human-Computer Interaction, Proceedings of CHI2003, Conference on Human Factors in Computing Systems, Fort Lauderdale, Florida, April 5-10 which is also reaching out to and involving consultants, researchers and designers from industry. Their projects may result in artifacts whose application scope is that of becoming used by the general public, outside of the comforting walls of research laboratories. These two cases illustrate that HCI tends to involve the academic researcher in design, as well as involving the designer from industry in $\mathrm{HCI}$ research. Because of this, we argue that HCI needs to be understood and acknowledged as a design-oriented field of research. If the role of design becomes neglected, HCI research may forgetfully become modeled upon the natural or social sciences. These do not typically embrace a proper or elaborate understanding of what design is, nor do they provide insight into what the role of design in research is. Hence, while design-orientation seems to be at the heart of our discipline, we argue that the understanding of this approach to research in terms of philosophical, theoretical and methodological foundations is poor within the field and that issues of design have not yet received proper attention.

This paper intends to address what design 'is' and how it is related to HCI. First, we introduce and analyze three competing accounts from design theory of what design is, and second, we examine in detail the concept of sketching as the archetypal activity of the design approach, and how it helps us grasp design work more properly as a kind of dialogue. Finally, to set out an as-yet-largely-absent discussion on the role and character of design in HCI, we propose to make a distinction between the conduct of Design-oriented Research and Research-oriented Design.

\section{The Design-oriented Attitude}

An initial approach to the question of design and designorientation in HCI research is to emphasize that design is a matter of making; it is an attitude to research that involves the researcher in creating and giving form to something not previously there. This process of making calls for a certain level of 'involvement', which metaphorically resembles the way carpenters must be directly involved with the materials of carpentry; its physical tools, techniques, and materials.

To design, again not unlike carpentry, is to consciously aim to create and give form to previously nonexistent artifacts $[8,20,27,36]$. Thus, at a high level of abstraction, designorientation is about being proactive in one's research; it is to take an active stance and to bring about intentional change. In doing so, design-orientation by definition implies a commitment to technology and technological development that goes beyond critique [8]. 


\section{THREE ACCOUNTS OF WHAT 'IS' DESIGN}

Adopting the design-oriented attitude has a number of implications on the way HCI research is both perceived and carried out, which go beyond our initial definition. To reveal some of these implications, it is helpful to turn to design theory. Here, we find what appears to be three competing accounts that provide different but equally important attempts to seize and conceptualize what the vibrant discourse of design really 'is' and what it is designers really 'do' when they design. These accounts are here named the conservative account, the romantic account, and the pragmatic account. These will now be considered (see Figure 1 for a summary).

\section{The Conservative Account}

From what could be called a conservative account, to be design-oriented is consciously to seek to intervene and manipulate [1], aiming to convert an undesired situation into a desirable one [34]. Here, design is thought of as a scientific or engineering endeavor, borrowing methodology and terminology from the natural sciences, mathematics, and systems theory, drawing on a philosophical base in rationalism.

According to this account of design, the design process is supposed to progress gradually from the abstract (requirements specifications) to the concrete (resulting artifacts). Progress is achieved through following a series of well-described, discrete, rational, and structured methodological steps [25]. Hence, the conservative account assumes that there is a 'problem' to be solved, and that descriptions of this problem can be comprehensively and accurately produced, if possible in the form of a structured requirements specification [25], which is then fed into the design process. The undertaking of the designer or the group of designers is to find, following the requirements specification, solutions to the described problems that may feasibly be carried out within the boundaries of the design project's constraints, including issues of cost, time, and performance. Design takes on the character of being a problem-solving activity; something that begins when a problem has occurred. The problem, in this view, is seen as given when design begins. For instance, some hold that "to have a problem implies ... that certain information is given to the problem solver: information about what is desired, under what conditions, by means of what tools and operations." [28, p. 73]

According to Alexander [1], these methodological steps can be abstracted down into two major processes. First, the designer is involved in analysis of the problem, a kind of 'breaking down' activity. That is, to seek to break down the initially ill-defined and unstructured area of the design problem into more manageable constituents. Second, the designer is involved in synthesis of a solution. This stage is a 'building up' activity, in which the designer builds upwards towards a solution to the overall design problem by solving each and every part of the set of smaller problems found during analysis. The Design Methodology movement-which took off from the work of Alexander [1] and Jones $[19,20]$-focuses on the importance of transparency and structure in this process. Cross [11, p. vii] talks about design methodology's concerns as "the study of how designers work and think; the establishment of appropriate structures for the design process; the development and application of new design methods, techniques, and procedures; and reflection on the nature and extent of design knowledge and its application to design problems." Design methods in this tradition are generally normative, and often include boxes-and-arrows diagrams [20]- specifying what activities to perform and in what order these activities should be performed - as well as generic design principles such as guidelines. This suggests that according to the conservative account, it is possible to externalize the rationality of design work into guidelines and by doing so transfer the skills of experienced designers to the inexperienced [35].

Hence, design methods typically assert design as a stringent process of systematic and controlled collection of information from which a problem is identified and objectives of the design process established. From this, the design solution-following the principles of logical deduction and mathematical optimization techniques-is thought to be more or less computed [14].

Under the process-oriented conservative account, methodology and structure are at the heart of understanding and practicing design, and the view of the designer is that of an engineer or a natural scientist. A good designer in this tradition is someone who is able to follow prescribed action. This tends to deemphasize the role of the designer, striving towards a disembodied design process built on structured methods and externalized guidelines rather than on the skills and judgment of individual designers [25, 35]. As such, the conservative account of design is highly impersonal, the designer is seen as 'glass box' [20], and every step in the process is suggested as rational and possible to describe.

\section{The Romantic Account}

Contrary to the conservative account, the romantic account of design gives prominence to the role of the designer. Here, they are seen as imaginative masterminds equipped with almost magical abilities of creation. This account nourishes the idea of 'creative geniuses', a legacy of the Enlightenment, as a reaction against whose intrinsic rationalism romanticism paradoxically took off as a movement. In addition to changing poetry, the novel, drama, painting, sculpture, and music, romanticism also reawakened people's interest in mythology, nationalism, folklore, the medieval, the exotic, and of course, also in nature, especially its mystical elements.

As romanticism came to develop however, the reaction became more of an alternative strand aside the rationalism promoted by the Enlightenment than a proper substitute for it. For the purposes of this paper, it is important to notice that individualism - that is, concerns of the individual and of individual identity - sprang from romanticism. In its 
emphasis on the individual, romanticism understands the key human abilities to be imagination over abstract reasoning and creativity over rational problem solving. Designers are seen as creative individuals with unusual talents, who often have to fight opposition in order to defend their unique creativity and artistic freedom [8]. This suggests art to be a better role model for design than science [9]; that designers should be compared with painters, composers, and poets, rather than with scientists or engineers. Creativity and imagination are hence seen to be the human abilities that impel design, whereas the issue of methodology is treated cautiously.

Following romanticism, this account suggests that the process of design involves a certain mystical element; it is by no means the fully rational and explicable process suggested by the conservative account. It is on the contrary somewhat mystical in its character, and it is not necessary to try to uncover this proposed mystical element, for the reason that, like golfers, designers might come to lose their swing if they think too much about what it is they actually do when they design. This account of design can be thought of as 'black boxed' [20] - the designer is someone who is able to generate creative designs but not able to, or at least not interested in, explaining how they came about.

Rather than by process, the design process is guided by the designer's values and taste, where the product becomes judged according to issues of quality and aesthetics [32, 35]. Hence, the romantic account of a design-oriented approach to HCI research trades in creativity and individuality over methodology and control, aesthetics and individual judgment over transparency and logical reasoning. The content of design (the product) and the human creator (the designer) are accentuated, whereas the process of producing the product is opaque. Louridas [24, p. 520] provides a statement of the relationship between art and design that follows the romantic account, including the suggested mystical elements of the relationship: "Design is related to art. This relation is what makes design what it is: design is not just about the creation of useful artifacts: it is equally about the creation of beautiful artifacts. Utility and aesthetics intertwine in the design process; but it is not clear how."

\section{The Pragmatic Account}

According to the pragmatic account, design is about being engaged directly in a specific design situation. It holds that design is always carried out somewhere in particular. This 'situatedness' locates the design process in a world which is already crammed with people, artifacts, and practices, each with their own histories, identities, goals, and plans.

Rather than science or art, under the pragmatic account design takes the form of a hermeneutic process of interpretation and creation of meaning, where designers iteratively interpret the effects of their designs on the situation at hand [10]. It is a reflective conversation with the materials of the design situation $[31,32,33]$. This view is related to Lévi-Strauss's concept of a 'bricoleur' [23]; someone who makes do with what is available or encountered in a specific situation: "[The Bricoleur's] universe of instruments is closed and the rules of his game are always to make do with 'whatever is at hand', that is to say with a set of tools and materials which is always finite and is also heterogeneous [...] The set of a 'bricoleur's' means $\ldots$ is to be defined only by its potential use." [23, p. 17-18] Like Schön's notion of reflective conversation, the bricoleur operates from the available means (the concrete tools and materials offered by a specific design situation) but treats them abstractly, by seeking to determine and redefine the roles they can play in the given situation by entering into a dialogue with them [23]. Ihde discusses bricolage as the skill to take on multiple views; possessing a compound eye [18].

Drawing on a philosophical base in pragmatism, the pragmatic account understands tacit and pre-reflective knowledge of everyday life and work - the spontaneous, intuitive performance of the actions of everyday life, termed knowing-in-action [31] — as the main elements of knowledge and as such providing the key for understanding design. Rather than leaning on theories and methodology for guidance, Schön suggests that "reflection-in-action ... is central to the 'art' by which practitioners sometimes deal well with situations of uncertainty, instability, uniqueness, and value conflict" [31, p. 50]. The pragmatic account focuses on the situatedness of the designer in the life-world and brings to light the interweaving of roles, practices, and technologies involved in design. The designer in the pragmatic account can be thought of as a 'self-organizing system' with constructive as well as reflective skills [20].

\begin{tabular}{|c|c|c|c|}
\hline & $\begin{array}{l}\text { Conservative } \\
\text { Account }\end{array}$ & $\begin{array}{l}\text { Pragmatic } \\
\text { Account }\end{array}$ & $\begin{array}{l}\text { Romantic } \\
\text { Account }\end{array}$ \\
\hline 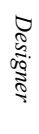 & $\begin{array}{l}\text { An information } \\
\text { processor; a 'glass } \\
\text { box' }\end{array}$ & $\begin{array}{l}\text { A reflective, know- } \\
\text { how bricoleur; a } \\
\text { 'self-organizing } \\
\text { system' }\end{array}$ & $\begin{array}{l}\text { A creative, } \\
\text { imaginative genius; } \\
\text { an artist; a 'black } \\
\text { box' }\end{array}$ \\
\hline$\frac{5}{\frac{9}{2}}$ & $\begin{array}{l}\text { Ill defined and } \\
\text { unstructured; to be } \\
\text { defined }\end{array}$ & $\begin{array}{l}\text { Unique to the } \\
\text { situation; to be set } \\
\text { by the designer }\end{array}$ & $\begin{array}{l}\text { Subordinate to the } \\
\text { final product }\end{array}$ \\
\hline $\begin{array}{l}2 \\
0 \\
\vdots \\
\vdots \\
2\end{array}$ & $\begin{array}{l}\text { A result of the } \\
\text { process }\end{array}$ & $\begin{array}{l}\text { An outcome of the } \\
\text { dialogue; integrated } \\
\text { in the world }\end{array}$ & $\begin{array}{l}\text { A functional piece } \\
\text { of art }\end{array}$ \\
\hline $\begin{array}{l}7 \\
0 \\
0 \\
0 \\
0\end{array}$ & $\begin{array}{l}\text { A rational search } \\
\text { process; fully } \\
\text { transparent }\end{array}$ & $\begin{array}{l}\text { A reflective } \\
\text { conversation; a } \\
\text { dialogue }\end{array}$ & $\begin{array}{l}\text { Largely opaque; } \\
\text { mystical }\end{array}$ \\
\hline 永 & $\begin{array}{l}\text { Guidelines; design } \\
\text { methods; } \\
\text { scientific laws }\end{array}$ & $\begin{array}{l}\text { How each problem } \\
\text { should be tackled; } \\
\text { compound seeing; } \\
\text { experience }\end{array}$ & $\begin{array}{l}\text { Creativity; } \\
\text { imagination; craft; } \\
\text { drawing }\end{array}$ \\
\hline $\begin{array}{l}\frac{0}{2} \\
\frac{2}{3} \\
0 \\
\frac{0}{2}\end{array}$ & $\begin{array}{l}\text { Natural sciences; } \\
\text { engineering; } \\
\text { optimization } \\
\text { theory }\end{array}$ & $\begin{array}{l}\text { Bricolage; human } \\
\text { sciences; sociology }\end{array}$ & $\begin{array}{l}\text { Art; music; poetry; } \\
\text { drama }\end{array}$ \\
\hline
\end{tabular}

Figure 1: Summarizing Table (in part based on [11]) 


\section{RELATIONSHIP BETWEEN RESEARCH AND DESIGN}

Design seems to have a role to play in almost every part of research, also in efforts which are not explicitly designoriented. In the natural and behavioral sciences, scientists must design experiments before they may be carried out and analyzed. This involves the researcher in designing a population of subjects, designing independent and dependent variables, and sometimes also designing the environment in which the experiment takes place. Any surveys and questionnaires appearing in the study must too be designed. In addition, natural scientists sometimes need to design their own instruments $[17,21]$, similarly to how HCI researchers need to design research prototypes in order to be able to perform tests and evaluations. Design is also at the heart of such disciplines as engineering, computing science, architecture, and medicine, which are often argued to be related to science. $\mathrm{Be}$ it combustion engines, compilers, bridges, or dental implants, they must all be designed. While design seems to be involved in many scientific practices, does that mean that design is a science?

\section{Limits of Design as Science}

In design, the struggle to mimic science is both most prominently advocated and critically examined by Simon, for whom the goal is explicitly to strive towards a "science of design" [34, p. 55]. Such a design science should be an "analytic, partly formalizable, partly empirical, teachable doctrine about the design process." [34, p. 58] In this highly influential work, Simon rests on the natural sciences to vindicate the new science of design, for instance by affirming the primacy of empirical testing [9], while at the same time somewhat paradoxically arguing that the design disciplines of the time had become too oriented towards the natural sciences. Or rather, according to Simon, they had become oriented towards the natural sciences, but in a way which was only to their detriment: "Engineering schools have become schools of physics and mathematics; medical schools have become schools of biological science; business schools have become schools of finite mathematics." [34, p. 56] To gain academic respectability by acquiring a scientific subject, the design disciplines had drifted away from their subject matter - the design of the artificial. The solution, according to Simon, must be for design to engage in a science of its own: a science of the artificial. But is design then best understood in terms of the natural sciences? Is design a science? From the perspective of interactive systems design, mimicking the natural sciences appears to be a valid approach. After all, computer science is generally considered a natural science, as computer algorithms can be studied and tested in the same way as for instance mathematical formulas, laws of nature, or chemical substances. Coyne observes the similarity with scientific inquiry: "the concept of finding a fit between a form and its context I suggested with the same assurance as the suggestion that a scientist compares two items of data, or compares the prediction of a theory with the results of an experiment. Design variables ... are presented as if they are variables in some scientific equation." [8, p. 220]
While advocating a science of design, Simon however disliked the tendency of the engineering disciplines at the time to have espoused the scientific goals and the methodologies for achieving them of the natural sciences. By doing so, according to Simon, they had started to overlook and drift away from their focal activities, designing the artificial [34].

Ehn, on the other hand, rejects the whole idea of design as having much in common with the natural sciences [13]. Taking off from Simon's suggestion that "everyone designs who devises courses of action aimed at changing existing situations into preferred ones" [34, p. 54], he suggests that in order to learn what Simon has in mind with 'preferred situation', one has to consider and integrate into any science of design typical subject matters of the human sciences, including issues of authority, power, control, labor, and in what social and historical settings a particular design effort takes place. Whereas computer algorithms can be studied by the natural sciences, the behavior of neither the individual designer nor the organization that constructs them are well captured by such an approach $[8,13]$.

\section{Limits of Design as a Transparent Process}

The traditional conception of the design process, strongly rooted in the conservative account, is to envision design work as divided into three distinct stages. The designer, according to this view, should first be involved in analyzing a problem, then in synthesizing a solution, and finally in evaluating the outcome [1]. Jones [20, p. 63] holds that "one of the simplest and most common observations about designing... is that it includes the three essential stages of analysis, synthesis, and evaluation. These can be described in simple words as 'breaking the problem into pieces', 'putting the pieces together in a new way' and 'testing to discover the consequences of putting the new arrangement into practice." In this, Jones expresses a characteristic conservative conceptualization, advising a sequential and linear order among the activities involved in design. This layout of the design process has been and still is highly influential, especially for approaching design in the engineering disciplines. But also in fields such as architecture, industrial design, information systems development, and software engineering, elaborated versions of the three-stage process have had a tendency to dominate the methodological understanding of design.

Nonetheless, even within the design methodology movement itself the failures of these structured design methods have been well documented $[5,6,13,22,30]$. There is also a widespread practical discontent with the process-oriented understanding of design suggested by the design methodology movement [14], where numerous case studies of actual design projects suggest that neither do designers work in the way suggested by the design methodology movement, nor would it be possible for them to work in the prescribed manner $[2,5,13,14,22]$. The most important problem seems to be the focus on process over people, product, and content. As design decisions 
seem often to be based on the content of a specific design situation, as suggested by the pragmatic account, a processbased approach which by nature and necessity must be forgetful of content would seem of only limited value [12]. In addition, some have argued that "the result of any process will never be better than the people who participate in the process $[\ldots]$ the skills and abilities of the designer determine the quality of the final [product]." [26, p. 14]

Noticeable, both Jones [20] and Alexander [2], the founders of the design methodology movement, acknowledge problems with the design methods. While still claiming the need for such methods, Jones notes that there "is not much evidence that they have been used with success, even by their inventors." [20, p. 27] To contrast the problems of the structured design methods, some have advocated the use of less formal, so-called 'second generation' design methods $[5,6]$. These methods - which include such activities as workshops, brainstorm sessions, synectics, checklists, and the use of specific environments to nurture creativity or for improving collaborative design $[8,26]$ - are intended to assist designers to collaborate and to be creative, rather than to systematize and formalize design work. Others have suggested that methods should be seen primarily as tools for learning. By learning a new method, designers are thought to extend their languages and repertoires of tools for different design situations: "Even more powerful is learning a method to the level where you can go beyond the method as stated. [...] At that level of method use, methods need not be confining or overly prescriptive." [26, p. 18]

Does Iteration Maintain Design as a Rational Activity? Traditionally, the concept of iteration is also used as an add-on, an extension, to overcome some of the recognized problems of the structured design methods, which basically allows the designer freedom to move between the stages of analysis, synthesis, and evaluation. It is a response to the recognition that understanding and describing the problem, finding a resolution, and implementing a solution do not occur straightforwardly or by applying a set of processes in a linear manner as suggested by the conservative account.

An iterative design process hence still involves the designer in all of the three processes of analysis, synthesis, and evaluation, but it does not do so in a linear fashion. The designer can chose to go back from synthesis to analysis, from evaluation to synthesis, and so on. Adding iteration to conservative design methods is necessary because of the apparent problem designers face when trying to use them; that one does not really know the problem until one starts working on its solution. But in doing so one goes against the original purpose of the method; to infer order among the activities of design. If its linearity is abandoned, what one has left is simply a list of activities included in design, but a list which is unordered and unstructured. In effect, the designer is left with the fact that design seems to consist of several activities that are inseparable and intertwined. In this sense, the idea of adding iteration to a structured design method seems in itself contradictory [14].
But if it is important to be able to go back from synthesis to analysis, then design is just as much about finding a problem as it is about developing a solution. As design does not proceed in ordered stages, it follows that analysis, synthesis, and evaluation cannot be thought of as clearly separated. Design becomes problem setting as much as problem solving [31]. If design in this way is seen as the process of unfolding the problem setting/problem solving pair, it makes sense to see the designer as being involved in a conversation - a dialogue - rather than in a structured and linear process of moving from the abstract to the concrete, regardless of whether or not iterations are allowed.

\section{SKETCHING AS ARCHETYPAL DESIGN ACTIVITY}

To better capture and understand the nature of design work, it becomes necessary to consider what is in this paper proposed as an archetypical activity performed in all design work, namely sketching. Here, sketching will not be regarded primarily as a useful tool, technique, or skill that is available to designers, but rather as the way in which designers think. After the importance of sketching has been established, it will follow to come to consider design more as a dialogue than as a set of rigid and transparent processes. In laying out these fundamentals, aspects that by some might be considered 'unscientific' or 'irrational'and which as such generally appear to be problematic elements in research processes - will emerge as being at the heart of design-orientation. To the best of our knowledge, concealing the importance of these archetypal activities is a disservice to any attempt at grasping the role of design as a focal element of HCI research.

\section{Sketching as Design Thinking}

In design fields such as architecture and industrial design, sketching has long been recognized as a core professional skill [36]. Design theory typically separates the kind of sketching which we will be concerned with here-that is occurring mostly in the early part of design and envisioned as primarily a tool for thinking - and the drawings that are produced in later stages, for public communication and as presentation aids [15]. The traditional view is to consider sketching simply as a way to externalize 'images' thought to be already present in the mind of the designer. Sketching then becomes a useful way in which form, appearance, and character of artifacts that are as yet intangible may be transferred from the designer's mind onto some lasting medium. Hence, in this view sketching works as a tool or technique useful for communicating with other designers and with customers as it provides a shared language which has no equivalent in ordinary, spoken language, but which allows designers to express themselves. Sketching should however not merely be seen as a tool for communication. In design work, sketching is far more important than that. Sketching has even been considered by some to be the very essence of what design work is all about [31]. As Black affirms: "Right from the earliest stages of tackling a problem, designers' thinking is mediated by the sketches or visible notes that they make to familiarize themselves with the material they are manipulating." [4, p. 284] 
But it is important to realize that such a 'familiarization' is not only a matter of one-directional externalization from the mind of the designer onto paper: sketching is also reading and interpreting the sketch, explaining it and eventually rephrasing it. Sketching is hence a matter of "externalizing ideas and interpreting external representations as ideas" [36, p. 14], a process Goldschmidt sees as a dialectic between different modes of 'seeing', between seeing-as and seeing-that [15].

Sketching is hence not simply an externalization of ideas already in the designer's mind, but on the contrary a way of shaping new ideas. In this dialectic, the sketch itself takes on a kind of 'middle ground' between the designer's vision - the parti or guiding image - and how it becomes realized into a coherent whole, a format $[3,36]$. The sketch is a reflection of this guiding image, but with which it is not and cannot be identical. According to Arnheim, it is this discrepancy that makes sketching such a useful instrument for the designer, and which allows experimentation with the whole and particular details, as well as with the relationship between them [3]. The materials in this way come to 'talk back' to the designer [33]. Sketching thus grows to be both the way designers 'work' and 'think'. It is how they get to know the materials of the design situation as well as how a parti comes to materialize in the world. Hence, sketching is a process, a kind of inquiry, rather than simply a matter of externalization - a document, a sketchwhich reports thinking that took place somewhere else.

\section{Prototyping: $\mathrm{HCl}$ Sketching}

We argue that sketching is also a widely applied way of thinking also in HCI, but which is habitually neglected and only rarely discussed. This may be because sketching in HCI differs in some ways from sketching in other design fields - the need to deal with issues such as interactivity, temporality, tangibility, immersion, sound, and hapticsand that it accordingly may be difficult to distinguish as sketching. As these are difficult to capture using pen and paper, sketching in HCI tends to be termed 'prototyping' and employs different techniques, tools, and materials, ranging from cardboard modeling to visualizations and computer programming languages [16, 37].

For the success of sketching, an often argued factor is that it in its basic form requires very little in terms of technological support (in fact, just a pen and a paper) as well as very little from the environment (as any reasonable flat surface will do). A vital but overlooked factor-which is also why it requires so little-is that neither the sketch itself nor the technological tool used to create it is actually what is important. In reviewing prototyping in HCI, Houde \& Hill [16] comes to the telling conclusion that a limitation of the ordinary way of conceiving and talking about prototyping (i.e. sketching) is the tendency to focus on attributes of the prototype itself (i.e. the sketch), highlighting for instance which tools were used to produce it and if it is of high or low fidelity. In doing so, the vital dialogue becomes concealed under the sketch itself.

\section{DESIGN AS UNFOLDING}

If one accepts the importance of sketching in design work, it is also easier to understand and appreciate the argument that design is a kind of dialogue; a reflective conversation. But if design then is reconsidered in terms of Schön's problem setting and problem solving, it is important that they are not interpreted as two different or succeeding activities. They are rather intertwined in the activity of design, an inseparable pair only unfolded through the design dialogue. Design in this sense becomes more of a search for a symmetrical, coherent, and well-balanced whole [3] - a complete gestalt [36] - than a process of first setting up and then solving problems.

Using sketching to work out a coherent whole means putting ideas to use (externalization) but it also means that these ideas are put to a test (interpretation) $[14,31,36]$ : How about this? Would this damage the whole? The interpretation that unavoidably occurs when something is put to use is rarely explicit, as it is so embedded in use that we do not think of it as also a test [14]. If the use/test pair fails, the designer tries another approach, a new angle on the problem or on the problem setting. Failure only explicitly occurs when the designer is not able to approach the problem or the problem setting from a new angle; the designer has got stuck. Likewise, success is not measured in explicit terms, it stems from a lack of failure rather than an explicit achievement; from actions of one or many use/test pairs that do not suggest problems, endorsing the designer to move on [14]. The design dialogue thus unfolds; exploring the tension between details and the search for a coherent, well-balanced whole.

\section{THE ROLE OF DESIGN IN HCI RESEARCH}

Let us return to the role of research prototypes in HCI, discussed briefly in the introduction. Once implemented, the research prototype is typically used as a researchers' proof-of-concept as well as exposed to users to conduct evaluations. Although the latter, under current HCI standards, require substantial efforts in terms of experimental design, rigor, and control, the way the object of testing, the research prototype itself, is constructed seems not to be of equal interest. On the contrary, the act of actually bringing forth the prototype - the design processseems often obliterated from descriptions of research projects; research prototypes just seem to 'happen'. But how do theories turn into applications, fieldwork findings into a mobile support system, and evaluation results into new interfaces? The argument put forward here is that design neither happens by chance nor by one-to-one correspondence between for instance fieldwork findings and resulting artifact. Rather, the latter come into being through researchers getting involved in design, which cannot simply be understood as just one of the components of science. The design process tends to remain implicit as researchers are embarrassed by not being able to show evidence of the same kind of control, structure, predictability, and rigorousness in doing design as they are able to show in other parts of their research. 
Design is thus a well-established and widespread approach in HCI research, but one which tends to become concealed under conservative covers of theory dependence, fieldwork data, user testing, and rigorous evaluations. But how does design help HCI researchers move from fieldwork to prototype? Where in HCI is design?

\section{Is $\mathrm{HCl}$ in Design, or is Design in $\mathrm{HCl}$ ?}

The three accounts of design discussed above are different ways of trying to seize the same difficult phenomenon; the nature of design. Some have suggested that design is neither a science nor does it have particular bonds to the humanities, but that it needs to be considered as a 'third culture' [7], in which aspects of all the three accounts introduced play an important role. We argue that it is true that design-orientation cannot be seized if only one of these accounts becomes much emphasized over another, nor if one or more of these accounts are completely abandoned. Likewise, we do not improve our understanding of the role of design in HCI research if we think of it as a solely scientific conduct, a fully transparent process ("There's a one-to-one correspondence between our fieldwork findings and the prototype design!"). Nor do we gain much insight from black-boxing design, where it becomes a curious art performed by some creative genius ("Ken, our whiz programmer, thought this design up!"). Thirdly, neither does concealing design as an unimportant practical bustle with reality help us understand its role in research ("Then we designed the prototype. Ugh...it took forever! Anyway, here are the results of our meticulous evaluation!"). But this argument is not to say that design should be thought of as a hybrid discipline existing somewhere in between science and art - which is a very common misconception of design. It is more accurately to say that if one of the accounts is much emphasized, it tends to influence how we think of and explain what it is we do when we design, but that alone does not influence what design 'is'. Instead of thinking about design in terms of being on a continuum between science and art, it must rather be considered essentially as a tradition guiding action and thought, which spans across many disciplines of which HCI is only one.

It is a tradition of pro-activity; an active stance. It includes the archetypal activity of sketching by which the designer becomes involved in the reflective conversation needed to bring new artifacts into being. The role of design in HCI is thus to be found in the act of trying to unfold a coherent whole - a previously nonexistent artifact — from the various bits and pieces gathered in the process of research, but which simply put together do not by themselves form this whole. Fieldwork, theory, and evaluation data provide systematically acquired input to this process, but do not by themselves provide the necessary whole. For the latter, there is only design.

Design-oriented Research vs Research-oriented Design Finally, to emphasize the role of design in HCI, we want to propose that the field should make the distinction between the conduct of Design-oriented Research and Researchoriented Design. As noted, design is part of HCI conduct both when it comes to academic researchers as well as to consultants, applied researchers, and designers from industry. We argue, however, that both the role design plays and the main contributions that stem from these two conducts differ, but that HCI is at times forgetful about this difference. Figure 2 illustrates these different conducts.
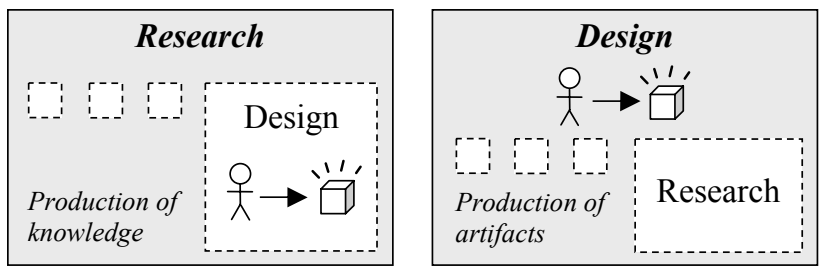

Figure 2. Design-oriented Research (left) vs. Researchoriented Design (right)

Design-oriented Research, what we see as the conduct of academic researchers, should have truth or knowledge of some sort as its main contribution, specifically such knowledge that would not have been attainable if designthe bringing forth of the research prototype-were not a vital part of the research process. In some ways, this resembles the way natural scientists may only be able to test a theory by first designing the tools with which to study the proposed phenomena. In design-oriented research, the knowledge that comes from studying the designed artifact in use or from the process of bringing the product into being is the contribution, while the resulting artifact is considered more a means than an end. It should include 'problem setting' as an important part, the possibility of exploring possibilities outside of the current paradigm.

In contrast, Research-oriented Design is a term we believe better illustrates the relationship between consultants, applied researchers, designers from industry, and HCI design. Unlike design-oriented research, research-oriented design naturally has 'problem solving' within a given paradigm as its main component, as problem setting may become practically infeasible in the commercial world for which the product is primarily tailored. It may relate to research, but have the production of new artifacts as its main motivation, not the production of new knowledge.

\section{CONCLUSIONS}

Design-oriented HCI may conceptually be thought of as a commitment to technology and technological development that goes beyond critique. Three competing accounts from design theory, which each try to capture what design 'is', were introduced; the process-oriented conservative account; the product-oriented romantic account; and the down-to-earth pragmatic account. Through an examination of the important role of sketching in design work, it was found that design involves the designer in a necessary dialogue with the materials of the design situation, from which the design problem and its solution are worked out simultaneously, as a closely coupled pair. Because of this, it was argued, the role of design in HCI must not simply be seen either as a question of problem-solving, as an artform, or as a bustle with reality: it is on the contrary an 
unfolding activity which demands deep involvement from the designer. Finally, it was proposed that the field of HCI needs to acknowledge the difference between the knowledge-generating conduct of Design-oriented Research and the artifact-generating conduct of Researchoriented Design. These have different purposes and prerequisites, and thus need different criteria for interpretation, discussion, and assessment.

\section{ACKNOWLEDGEMENTS}

The author wants to acknowledge John A. Waterworth, Erik Stolterman, and Victor Kaptelinin for valuable discussions. Thanks to Interactive Institute's Umeå Studio and Umeå Institute of Design for funding and support.

\section{REFERENCES}

1. Alexander, C. Notes on the Synthesis of Form. Harvard University Press, Cambridge MA, 1964.

2. Alexander, C. The State of the Art in Design Methods. DMG Newsletter 5(3), 1971, 1-7.

3. Arnheim, R. Sketching and the Psychology of Design. In Margolin, V. \& Buchanan, R. (Eds.) The Idea of Design. MIT Press, Cambridge MA, 1995.

4. Black A, Visible Planning on Paper and on Screen. Behavior and Info. Technology 9(4), 1990, 283-296.

5. Broadbent, G. Design in Architecture. John Wiley \& Sons, New York NY, 1973.

6. Broadbent, G. The Development of Design Methods. Design Methods and Theories 13(1), 1979, 41- 45.

7. Brockman, J. The Third Culture: Beyond the Scientific Revolution. Simon \& Schuster, New York NY, 1995.

8. Coyne, R. Designing Information Technology in the Postmodern Age. MIT Press, Cambridge MA, 1995.

9. Coyne, R. Technoromanticism: Digital Narrative, Holism, and the Romance of the Real. MIT Press, Cambridge MA, 1999.

10. Coyne, R. \& Adrian, S. Is Designing Mysterious? Challenging the Dual Knowledge Thesis. Design Studies, Vol. 12, No. 3, 1991, 124-131.

11. Cross, N. (Ed.) Developments in Design Methodology. John Wiley \& Sons, Chichester UK, 1984.

12.Dorst, K. \& Dijkhuis, J. Comparing Paradigms for Describing Design Activity. Design Studies, 16, 1995, $261-274$

13.Ehn, P. Work-oriented Design of Computer Artifacts. Arbetslivscentrum, Falköping Sweden, 1988.

14. Gedenryd, H. How Designers Work. Ph.D. Thesis, University of Lund, Lund Sweden, 1998.

15. Goldschmidt, G. The Dialectics of Sketching, Design Studies, Vol. 4, No. 2, 1991, 123-143.

16. Houde, S. \& Hill, C. What do Prototypes Prototype?. In Helander, M., Landauer, T. K., \& Prabhu, P. (Eds.) Handbook of Human-Computer Interaction. 2nd Ed, Elsevier Science, Amsterdam Netherlands, 1997.
17. Ihde, D. Instrumental Realism. Indiana University Press, Bloomington IN, 1991.

18. Ihde, D. Postphenomenology. North Western University Press, Evanston IL, 1993.

19. Jones, J. C. A Method of Systematic Design. In Jones, J. C. \& Thornley, D. (Eds.) Conference on Design Methods, Pergamon Press, Oxford UK, 1963.

20. Jones, J. C. Design Methods. Van Nostrand Reinhold, New York NY, 1970.

21.Kuhn, T. S. The Structure of Scientific Revolutions. University of Chicago Press, Chicago IL, 1962.

22.Lawson. B. How Designers Think. Butterworth Architecture, Oxford UK, 1980.

23. Lévi-Strauss, C. The Savage Mind. Transl. Weidenfeld, G., University of Chicago Press, Chicago IL, 1966.

24.Louridas, P. Design as Bricolage: Anthropology meets Design Thinking. Design Studies, Vol. 20, No. 6, 1999, $517-535$.

25. Löwgren, J. Applying Design Methodology to Software Development. (DIS'95, Ann Arbor) ACM Press, New York NY, 1995, 87-95.

26. Löwgren, J. \& Stolterman, E. Design Methodology and Design Practice. interactions, 1, 1999, 13-20.

27. Nelson, H. \& Stolterman, E. The Design Way.(In Press).

28. Newell, A. \& Simon, H. A. Human Problem Solving. Prentice-Hall, Englewood Cliffs NJ, 1972.

29.Parnas, D. L. \& Clements, P. C. A Rational Design Process: How and Why to Fake It. IEEE Transactions on Software Engineering 12(2), 1986, 251-257.

30. Rittel, H. W. J. Second-generation Design Methods. The DMG 5th Anniversary Report, DMG Occasional Paper No. 1, 1972, 5-10.

31.Schön, D. The Reflective Practitioner: How Professionals Think in Action. Basic Books, New York NY, 1983

32. Schön, D. Educating the Reflective Practitioner. JosseyBass, San Francisco CA, 1987.

33. Schön, D. Designing as Reflective Conversation with the Materials of a Design Situation. Knowledge-Based Systems, 5, 1992, 3-14.

34. Simon, H. A. The Sciences of the Artificial. MIT Press, Cambridge MA, 1969.

35. Stolterman, E. Guidelines or Aesthetics: Design Learning Strategies. Design Studies, Vol.15, No.4, 1994.

36. Stolterman, E. The Design of Information Systems: Parti, Formats and Sketching. Information Systems Journal, Vol. 9, No. 1, 1999.

37. Winograd, T., Bennett, J., De Young, L., \& Hartfield, B. (Eds.) Bringing Design to Software. ACM Press, New York NY, 1996. 